\title{
O Ensino Médio nos Municípios do Grande ABC Paulista: Análise e Interpretação de alguns Indicadores de Desempenho
}

\author{
An Evaluation of High school in State Schools in the Greater \\ ABC: Analysis and Interpretation of some Indexes of \\ Performance
}

Paulo Sérgio Garcia*, Leandro Campi Prearo, Maria do Carmo Romero e Marcos Sidnei Bassi

Universidade Municipal de São Caetano do Sul

\begin{abstract}
O Ensino Médio (EM) no Brasil se caracteriza pelo nível de ensino onde ocorrem as maiores discussões em virtude dos constantes problemas em relação ao acesso, à permanência, às altas taxas de reprovação e à qualidade do ensino. Este estudo, utilizando métodos mistos, revela e analisa a situação do EM das escolas estaduais do grande ABC Paulista. $\mathrm{O}$ foco da pesquisa está relacionado aos índices de reprovação, distorção idade-série, abandono escolar e ao desempenho das escolas no Exame Nacional do Ensino Médio (ENEM). Os resultados encontrados mostraram altas taxas de reprovação, de distorção e de abandono escolar, centralizados, sobretudo no primeiro ano escolar. Na região, a cada hora um aluno abandona o EM, revelando uma realidade empobrecida. A contextualização desses resultados indicou uma demanda que responsabiliza alunos, famílias, professores e gestores escolares. Paralelamente, os dados do ENEM revelaram que o pior desempenho ocorreu na área de Ciências da Natureza e que em todas as cidades analisadas o nível socioeconômico interferiu no desempenho das escolas, sinalizando que mesmo em uma das regiões mais ricas do país a condição social, econômica e cultural dos familiares interfere, em grande medida, nas aquisições cognitivas dos alunos. Esses resultados podem ser utilizados pelas autoridades políticas e educacionais para fomentar discussões sobre a melhoria deste nível de ensino.
\end{abstract}

Palavras-chave: Avaliação escolar, Ensino médio, Desempenho escolar, ENEM.

High school (HS) in Brazil is characterized by the level of education which has occurred the highest discussions due to the constant problems in relation to access, the permanence, the high failure rates, and the quality of education. This study, using mixed methods, analyzes the situation of the state high schools in region of great ABC Paulista. This research focus is related to failure rates, age-grade distortion (over-age), school dropout and school performance at the National High School Exam (ENEM). The results showed high failure rates, age-grade distortion and school dropout, centralized, especially in the first school year. In the region, every hour one student abandons the HS, revealing an impoverished reality. The contextualization of the results indicated a demand attributing the responsibility to the students, families, teachers and school managers. In parallel, the ENEM data showed that the worst performance occurred in the Natural Sciences area and that in all cities analyzed socioeconomic status interfered in school performance, indicating that even in one of the richest Brazilian regions, social, economic and cultural conditions of the parents interfere, largely, in students' cognitive acquisitions. These results can be used by the political and educational authorities to promote discussions on improving HS in Brazil.

Keywords: School evaluation, High school, School performance, Brazilian National Exam.

*Contacto: garciaps@usp.br

issn: $1989-0397$

www.rinace.net/riee/

https://revistas.uam.es/riee
Recibido:

29 de abril de 2016

$1^{\text {a }}$ Evaluación: 20 de julio de 2016

Aceptado: $\quad 9$ de agosto de 2016 


\section{Introduçãó ${ }^{1}$}

Os objetivos, fundamentos e as finalidades que orientam o Ensino Médio (EM) no Brasil foram delineados pela Lei de Diretrizes e Bases da Educação Nacional, de 1996, Lei ${ }^{\circ}$ 9.394/96 (LDBEN/96). O Art. 35, desta legislação, prevê o EM como etapa final da Educação Básica, em continuidade ao Ensino Fundamental. Recentemente, foi publicada a Resolução n. 2, de janeiro de 2012, estabelecendo as novas Diretrizes Curriculares Nacionais para este segmento, complementando a LDBEN/96. Em seu Art. 2, pode-se verificar que tais orientações se articulam com as Diretrizes Curriculares Nacionais Gerais para a Educação Básica (Dcneb, 2013) e reúnem princípios e fundamentos, que foram estabelecidos pelo Conselho Nacional de Educação, para orientar as políticas educacionais da União, dos Estados, do Distrito Federal e dos Municípios na elaboração, no planejamento, na implementação e na avaliação de programas e projetos curriculares das escolas que oferecem o Ensino Médio.

O EM apresentou grande expansão que foi iniciada ainda na década de 1990. No entanto, mesmo atualmente tal processo não pode ser considerado como universalizado ou democratizado. Há ainda inúmeros desafios a serem superados como as altas taxas de alunos fora da escola, currículo não atraente, baixos investimentos públicos, baixa remuneração para os professores, infraestrutura escolar inadequada, altas taxas de reprovação, de distorção idade-série e de abandono escolar, entre outros.

Nestas últimas três questões, o Brasil ainda tem muito para avançar. As taxas de reprovação no EM ainda são elevadas. Os esforços realizados de 2011 para 2014 conseguiram reduzir as reprovações médias no Brasil em apenas 1\% (14,2\% em 2011 13,2\% em 2014). No mesmo período, em relação à distorção idade-série, o avanço foi de somente $5 \%$ (37\% em 2011 - 32\% em 2014). Na questão do abandono escolar, os números de 2014 atingem 8,8\% de todos os jovens do Ensino Médio (esfera estadual). Esse número em 2011 era de 10,9\% (Censo Escolar, 2014).

O quadro também é limitante quando analisamos as escolas brasileiras na perspectiva dos dados do Exame Nacional do Ensino Médio. Estudo, em relação ao desenvolvimento dos alunos no exame (Viggiano e Mattos, 2013), revelou os baixos resultados dos jovens brasileiros em qualquer uma das cinco áreas analisadas (Ciências Humanas, Ciências da Natureza, Linguagem e Códigos, Matemática e Redação), com destaque negativo para as regiões Norte e Nordeste.

O Ensino Médio no Brasil tem se caracterizado pelo nível de ensino onde acontecem as maiores discussões face aos constantes problemas em relação ao acesso, à permanência, às altas taxas de reprovação e abandono escolar, à qualidade do ensino e à falta de identidade. Neste sentido, este estudo, utilizando dados do Censo Escolar na primeira fase, revela e analisa a situação do Ensino Médio das escolas estaduais do grande ABC Paulista. Uma região que compreende sete municípios, com alto nível socioeconômico e condições sociais acima da média de outras localidades brasileiras. A pesquisa centra-se nos índices de reprovação, distorção idade-série, abandono escolar e desempenho das escolas no ENEM. Os resultados encontrados são integrados a outras análises mais

\footnotetext{
${ }^{1}$ Projeto Financiado pelo Observatório da Educação do Grande ABC (São Paulo).
} 
detalhadas (segunda fase), que revelam as circunstâncias as quais eles foram produzidos. Trata-se da contextualização dos dados a partir daqueles que residem e atuam no cotidiano escolar: os diretores. Neste sentido, considera-se que os dados publicados pelo Instituto Nacional de Estudo e Pesquisa (Inep) oferecem pouco sentido se não forem analisados em uma moldura mais ampla, com interlocução com os fatores condicionantes de tais resultados, ou seja, as condições em que a aprendizagem dos jovens ocorre.

\section{O Ensino Médio e o ENEM}

O EM teve seus objetivos e fundamentos estabelecidos pela LDBEN/96 (Art. 35), pelas Diretrizes Curriculares Nacionais par o Ensino Médio (Resolução n. 2, 2012) e pelas Diretrizes Curriculares Nacionais Gerais para a Educação Básica (Dcneb/2013). O Art. $4^{\circ}$, da Dcneb, estabeleceu que as escolas devem estruturar seus projetos políticopedagógicos, considerando as finalidades previstas na LDBEN/96 para a consolidação e o aprofundamento dos conhecimentos já adquiridos; para o prosseguimento de estudos; para a preparação básica para o trabalho e a cidadania do educando; para o aprimoramento do educando como pessoa humana e o conhecimento dos fundamentos científico-tecnológicos.

Quanto às bases da oferta do Ensino Médio, o Art. 5 expressa a formação integral, o trabalho e a pesquisa como princípios educativos e pedagógicos, a educação em direitos humanos como princípio orientador, a sustentabilidade ambiental como meta universal, a indissociabilidade entre educação e prática social, a integração de conhecimentos gerais com os profissionais, o reconhecimento e aceitação da diversidade, a integração entre educação e as dimensões do trabalho, da ciência, da tecnologia e da cultura como base da proposta e do desenvolvimento curricular. A organização curricular, prevista no Art. 7, integra uma base nacional comum e uma parte diversificada, organizando o currículo em áreas de conhecimento (Art 8): Linguagens, Matemática, Ciências da Natureza e Ciências Humanas. Neste contexto, o tratamento metodológico deve evidenciar, de acordo com as Dcenb, a contextualização e a interdisciplinaridade.

De acordo com dados do Instituto Brasileiro de Geografia e Estatística e da Pesquisa Nacional por Amostra de Domicílios (IBGE/Pnad), em 2001 a taxa de atendimento dos alunos de EM, de 15 a 17 anos, era de 78,4\%, passando em 2013 para $81,5 \%$. A taxa líquida de alunos, jovens com a mesma idade matriculados na escola no ano correspondente à idade, no mesmo período, passou de 38,4\% para 55,5\%. Esses dados revelam que apesar haver um aumento no número de jovens matriculados nas escolas (mais de $80 \%$ ) somente um pouco mais de 55\% estavam cursando o EM.

Desses 55,5\% (5.903.692) de jovens que estavam frequentando a escola, aproximadamente, $63 \%$ eram considerados brancos e $75 \%$ estavam no quartil superior (25\% mais ricos), mostrando que os brancos e os mais ricos estavam mais presentes na escola de Ensino Médio. Entre os jovens de 19 anos que concluíram o EM, os dados mostraram que a taxa de conclusão em 2001 era de 32\% e em 2013 o número cresceu para $55,3 \%$. Dos jovens de 15 a 17 anos, 14,3\% (1.523.220) não tinham finalizado o EM ou não estavam estudando no ano de 2013. 
No Brasil, a grande maioria dos jovens do EM estudava na rede estadual em, aproximadamente, 18 mil escolas, que contavam com um pouco mais de 7 milhões de matrículas e, perto de, 3,5 milhões de alunos estavam localizados no Sudeste brasileiro.

Quanto à infraestrutura das escolas públicas de EM, 88,5\% possuíam abastecimento de água, $97,5 \%$ banheiro dentro do prédio e $91,8 \%$ água filtrada. Neste contexto, $56,4 \%$ das instituições de ensino possuíam biblioteca, $93,2 \%$ acesso à internet, 91,5\% laboratório de informática, 39,4\% acessibilidade, $75,5 \%$ quadra de esportes e 44,4\% laboratório de ciências (Censo escolar, 2014).

O Ensino Médio tem se caracterizado pelo nível de ensino onde ainda existem dificuldades de acesso, de permanência e de sucesso do jovem. Além disto, trata-se de um segmento que apresenta as altas taxas de reprovação, distorção idade-série, abandono escolar e falta de qualidade de ensino.

No contexto da reprovação de alunos, da distorção idade-série e do abandono escolar, as taxas ainda são elevadas, revelando falta de legitimidade deste nível de ensino, resultante, entre outras coisas, da crise socioeconômica, da falta de identidade do EM e de incentivos para esses jovens para permanecer na escola (Krawczyk, 2011). O Quadro 1 sintetiza alguns dados da realidade brasileira, de acordo com dados do Censo Escolar/Inep (2011, 2012, 2013 e 2014), sinalizando a ausência de uma política educacional e pedagógica para lidar com os problemas, entre outras.

Quadro 1. Taxas de reprovação, idade série e abandono

\begin{tabular}{lcccc}
\hline & $\mathbf{2 0 1 1}$ & $\mathbf{2 0 1 2}$ & $\mathbf{2 0 1 3}$ & $\mathbf{2 0 1 4}$ \\
\hline Taxas de reprovação & $14,2 \%$ & $13,2 \%$ & $12,8 \%$ & $13,2 \%$ \\
Distorção idade-série & $37 \%$ & $35 \%$ & $33 \%$ & $32 \%$ \\
Abandono escolar & $10,9 \%$ & $10,5 \%$ & $9,3 \%$ & $8,8 \%$ \\
\hline
\end{tabular}

Fonte: Elaboração própria.

Em relação aos estados, a distorção idade-série se apresenta elevada em alguns deles. Existem aqueles que estão abaixo de 5\% (São Paulo, Minas Gerais e Mato Grosso), aqueles que estão entre 5\% e 10\% (Santa Catarina), entre 10,1\% e 15\% (Goiás, Espírito Santo, Amazonas) e outros que superam os 15\% (Paraná, entre outros).

Salva, Ramos e Ramos (2016) mostraram no contexto do Rio Grande do Sul que as escolas de EM apresentavam altas taxas de reprovação, distorção idade-série e abandono escolar. O estudo, revelando as causas do afastamento dos jovens da escola, categorizou vários motivos. Entre eles está a necessidade de trabalhar prematuramente para auxiliar a família; a falta de diálogo com a escola, sendo que esta desconhece os interesses e a linguagem do jovem; os conteúdos escolares que não atendem às necessidades dos jovens; o descaso dos gestores quando os adolescentes sinalizam se evadir da escola, metodologias inadequadas; gravidez precoce; falta de clareza nas ações realizadas a fim de manter os alunos na escola. Em outro estudo, Néri (2009) revelou que o trabalho e a falta de motivação estavam entre os motivos mais sinalizados pelos jovens de 15 a 17 anos para não frequentar a escola.

Krawczyk (2011, p. 754) sugere que as deficiências e dificuldades do EM na atualidade estão relacionadas à "presença tardia de um projeto de democratização da educação pública no Brasil ainda inacabado, que sofre os abalos das mudanças ocorridas na 
segunda metade do século XX, que transformaram significativamente a ordem social, econômica e cultural, com importantes consequências para toda a educação pública".

\subsection{O Exame Nacional do Ensino Médio}

O Exame Nacional do Ensino Médio foi criado na esteira das políticas de avaliação da qualidade da educação brasileira, a partir da criação do Sistema Nacional de Avaliação (SAEB). Trata-se de um exame que visa realizar uma avaliação das competências básicas dos jovens com o foco na cidadania e, ao mesmo tempo, como uma "modalidade alternativa ou complementar aos exames de acesso aos cursos profissionalizantes pósmédios e ao ensino superior" (Brasil/Inep, 1998, p. 2).

O exame se tornou conhecido pela utilização de questões não tradicionais. Quando foi estabelecido, em 1998, o ENEM foi apresentado como uma nova estratégia para avaliar diretamente as competências dos alunos, definidas por um documento oficial como "modalidades estruturais de inteligência" (Franco e Bonamino, 1999, p. 29). Bizzo et al (2013, p. 416) sinalizaram que o exame foi recebido pela imprensa brasileira de forma positiva e amplamente promovido em impressos avulsos oficiais. Ele foi recebido não somente como uma estratégia para uma reforma educativa fundamentada em avaliação, mas sobretudo "como instrumento de reforma social, uma vez que supostamente iria ajudar os estudantes pobres a ingressar na educação superior e, além disso, também poderia direcioná-los para o mercado de trabalho”.

Em 2016, um pouco mais de 9 milhões estudantes se inscreveram no ENEM. Esses jovens concorriam a mais de 200 mil vagas no ensino superior público, em mais de 5.500 cursos, de mais de 125 instituições no Sistema Unificado de Seleção de Universidades públicas (SISU). Em 2014, o governo havia gastado mais de 450 milhões, quantia que foi disputada por empresas privadas especializadas em um processo que dispensa licitação, além da renúncia fiscal exigida para o fornecimento de bolsas de estudo do Programa Universidade para Todos (PROUNI).

O ENEM atualmente possui cinco áreas do conhecimento: Ciências Naturais e suas Tecnologias (CN), Linguagens, Códigos e suas Tecnologias (LC), Matemática e suas Tecnologias (MT), Ciências Humanas e suas Tecnologias (CH) e Redação (RE). Recentemente (2009), o exame sofreu alteração em função, entre outras coisas, da criação do SISU. Sua organização anterior previa a aplicação de 63 itens em um dia. A atual prevê 180 itens, aplicados em dois dias e ainda a obrigatoriedade da Redação. Com tal mudança, várias instituições de ensino superior começaram a adotar o exame como forma de ingresso. $\mathrm{O}$ exame engloba uma grande lista de competências e habilidades, juntamente com referências conceituais para o conhecimento disciplinar ("objetos de conhecimento").

Atualmente, o exame incorporou outras atribuições. A Portaria $n^{0}$ 109/2009 ampliou seus objetivos para três finalidades: a) avaliação do EM para subsidiar políticas públicas; certificação daqueles que estão fora da escola e avaliação classificatória para acesso ao ensino superior. Em 2014, mais de 60 mil participantes, em torno de 10\%, se inscreveram com o intuito de solicitar a certificação do Ensino Médio.

O ENEM deixou também de fazer uso da Teoria Clássica de Itens, neste caso da utilização simples do número de acertos nas questões, passando a usar a Teoria de Resposta ao Item (TRI), que aplica pesos diferentes a cada um dos itens utilizados no 
exame. A TRI realiza a redução da importância dos itens acertados pelos alunos ao acaso ou aqueles que são demasiadamente fáceis. A utilização da TRI e a elaboração do exame, utilizando as mesmas competências e habilidades, permite comparar dois exames em anos diferentes. Esta metodologia indica que o número de acertos na prova não tem correlação direta com a nota da parte objetiva. Neste caso, é necessário conhecer que peso foi atribuído para cada questão, sinalizando que dois jovens que obtenham o mesmo número de acertos podem ter notas diferentes, dependendo de quais itens cada um tenha acertado.

Lopes e Lopez (2010) sinalizaram que o ENEM pode influenciar os currículos da Educação Básica, criando algum tipo de controle sobre eles, pois o ingresso ao ensino superior é, decisivamente, influenciado pela composição desses currículos.

Neste sentido, em uma posição mais substancial, considera-se que o exame afeta mais incisivamente o EM, modulando, regulando e, às vezes, reduzindo os currículos das escolas às competências e habilidades requeridas nas provas. No mesmo contexto, é necessário considerar que ele interfere também nas práticas pedagógicas dos professores, incluindo aquelas de avaliação. Em outras palavras, muitos professores do EM ensinam com o foco naquilo que é exigido no ENEM, naquilo que "cai na prova". A avaliação do aluno na escola, neste contexto, é regulada e, muitas vezes, repleta de questões que já fizeram parte do exame em alguma edição.

Outros autores, entre eles Vianna (2003), Viggiano, Guariglia e Mattos (2010), realizaram pesquisas sobre a matriz de criação do exame e, simultaneamente, debateram sobre o papel do exame situado nas políticas de avaliações de larga escala realizadas no Brasil. Outros pesquisadores avaliaram os pressupostos teóricos da prova com o foco na avaliação por competências. A evolução do ENEM foi analisada por Viggiano, Guariglia e Mattos (2011) e Ramalho e Núñez (2011) apresentaram várias discussões sobre a dimensão conceitual do exame. Por fim, Gonçalves Jr. (2012) identificou, avaliando o ENEM de 2009, as competências analisadas e discutiu o desempenho dos jovens sobre elas.

O estudo de Viggiano e Mattos (2013) mostrou que no âmbito nacional o pior desempenho dos alunos no ENEM ocorreu na área de Ciências da Natureza (488 pontos). A individualização desses dados por região revela que no Norte do país a média foi 467 pontos, no Nordeste 473, no Centro Oeste 482, no Sul 500 e no Sudeste 503 pontos, com desempenho maior para essas duas últimas. Nesta pesquisa, os autores concluíram que esta área é uma das mais influenciadas pelas desigualdades sociais entre as regiões brasileiras.

Em outro estudo, Travitzki (2013), ao analisar os dados do ENEM 2009 e 2010, revelou que o nível socioeconômico (renda familiar, escolaridade dos pais e outros fatores) explicava $80 \%$ da média das escolas com mais de 10 alunos e os outros $20 \%$ eram creditados ao efeito escola. Nesta pesquisa, o autor tinha o intuito de conhecer até que ponto o ranking de escolas do ENEM tinha validade como indicador de qualidade escolar. Travitzki estava propondo outro ranking de escolas para ENEM, com base na nota adquirida, porém mais justo, equitativo e informativo. 


\section{As cidades do Grande ABC Paulista}

O Grande $\mathrm{ABC}$ Paulista, também conhecido como $\mathrm{ABC}$ Paulista, região do Grande $\mathrm{ABC}$ ou ainda $\mathrm{ABCD}$, é formado por sete cidades situadas em uma área de $635 \mathrm{~km}^{2}$ e com 2,5 milhões de habitantes. Está localizado na região metropolitana do estado de São Paulo. Santo André, São Bernardo do Campo, São Caetano do Sul, Diadema, Mauá, Ribeirão Pires e Rio Grande da Serra são municípios com diferentes características. A cidade de São Caetano do Sul, a menor em área, possui o maior IDH-M (2010). A região possui um PIB industrial que é considerado o segundo do estado e o terceiro do país (aproximadamente $\mathrm{R} \$ 27$ bilhões). A Tabela 1 sintetiza os dados das características da região do Grande ABC Paulista.

Tabela 1. Características demográficas das cidades

\begin{tabular}{|c|c|c|c|c|c|c|c|}
\hline MuNicíPIO & PoPUlaÇÃo & $\begin{array}{c}\text { ÁREA } \\
\text { TERRITORIA } \\
\text { KM2 }\end{array}$ & PIB (MILHÕES) & $\begin{array}{c}\text { PosIÇão } \\
\text { DO PIB }\end{array}$ & IDH-M 2010 & $\begin{array}{c}\text { ANOS } \\
\text { MÉDIO } \\
\text { DE } \\
\text { ESTUDO }\end{array}$ & $\begin{array}{c}\text { ACESSO À } \\
\text { INTERNET } \\
(\%)\end{array}$ \\
\hline Santo André & 704.942 & 175,781 & 17.664 .718 & $33^{\mathrm{a}}$ & $0,815\left(8^{\circ}\right)$ & 10 & 72,7 \\
\hline São Bernardo & 805,895 & 409,478 & 36.337 .338 & $14^{\mathrm{a}}$ & $0,805\left(16^{\circ}\right)$ & 10 & 81,7 \\
\hline São Caetano & 156.362 & 15,33 & 11.762 .744 & $48^{\mathrm{a}}$ & $0,862\left(1^{\circ}\right)$ & 11 & 73,4 \\
\hline Diadema & 406.718 & 30,796 & 11.786 .624 & $47^{\mathrm{a}}$ & $0,757\left(184^{\circ}\right)$ & 08 & 57,2 \\
\hline Mauá & 444.136 & 61,866 & 7.633 .782 & $79^{\mathrm{a}}$ & $0,766\left(134^{\circ}\right)$ & 09 & 65,2 \\
\hline Ribeirão Pires & 118.871 & 99,119 & 1.978 .256 & $287^{\mathrm{a}}$ & $0,784\left(58^{\circ}\right)$ & 09 & 62,6 \\
\hline Rio Grande da Serra & 47.142 & 36,341 & 529.413 & $816^{\mathrm{a}}$ & $0,749\left(245^{\circ}\right)$ & 09 & $52,6 \%$ \\
\hline
\end{tabular}

Fonte: Elaboração própria, IBGE - 2011.

Na região do Grande ABC, em geral, os municípios estão bem classificados em relação ao IDH-M, que tem o intuito de medir o grau de desenvolvimento econômico e a qualidade de vida (Educação e longevidade) oferecida à população. Quanto ao nível de renda per capita média das populações, São Caetano possuía $\mathrm{R}$ \$ 2.349,00, Santo André $\mathrm{R} \$$ 1.499,00, São Bernardo R\$ 1.394,00, Ribeirão Pires $\mathrm{R} \$ 974,00$, Diadema R $\$ 917,00$, Mauá $\mathrm{R} \$$ 815,00 e Rio Grande R \$ 747,00 (Observatório da Educação do Grande ABC, 2015).

A região possuía, aproximadamente, $50 \%$ dos postos de trabalho no setor de serviços (RAIS, 2013), sua população tinha, em média, mais de nove anos de estudo e com avanços no serviço de distribuição de acesso à internet. No entanto, trata-se ainda de área com altas desigualdades. Dados do Observatório da Educação do Grande ABC, de 2015, relacionados à desigualdade social (índice Gini), medida que varia entre 0 e 1 (0 não desigualdade e 1 maior desigualdade possível), revelaram que as cidades de Santo André $(0,53)$, São Bernardo $(0,54)$, São Caetano $(0,54)$ com maiores rendas, eram aquelas que apresentavam maior desigualdade social (Diadema: 0,43, Mauá: 0,44 e Rio Grande da Serra: 0,39).

A região do $\mathrm{ABC}$ tem sido alvo de vários estudos. Uma dessas pesquisas mostrou dados do Índice de Desenvolvimento da Educação Básica (IDEB) observados, as metas estabelecidas pelo Inep e as proporções de alunos que aprenderam adequadamente na competência de leitura e interpretação e na de resolução de problemas, sinalizando que este indicador no Ensino Fundamental I tem tido aumento gradual, constante e contínuo, demostrando avanços significativos, mas no Ensino Fundamental II a situação era mais de estagnação (Garcia et al., 2016). 
A região do ABC possuía em 2014, de acordo com dados do Censo Escolar (Inep, 2014), 224 escolas estaduais de Ensino Médio regular. Essas estavam localizadas em Santo André (55), São Bernardo (65), São Caetano (11), Diadema (35). Mauá (33), Ribeirão Pires (16) e Rio Grande da Serra (9).

O Quadro 2 revela as quantidades de matrículas por município no grande ABC entre 2011 e 2014:

Quadro 2: Matrículas Ensino Médio (2011 - 2014) escolas estaduais

\begin{tabular}{lrrrr}
\hline \multicolumn{1}{c}{ MUNIĆ́PIO } & \multicolumn{3}{c}{ MATRÍCULAS ENSINO MÉDIO } \\
\cline { 2 - 5 } & $\mathbf{2 0 1 1}$ & $\mathbf{2 0 1 2}$ & $\mathbf{2 0 1 3}$ & $\mathbf{2 0 1 4}$ \\
\hline Santo André & 25.047 & 25.032 & 24.574 & 23.945 \\
São Bernardo do Campo & 32.593 & 32.431 & 32.273 & 32.385 \\
São Caetano do Sul & 5.735 & 5.430 & 5.117 & 5.024 \\
Diadema & 18.494 & 19.033 & 19.054 & 19.080 \\
Mauá & 17.726 & 17.467 & 17.928 & 18.080 \\
Total & 99.595 & 99.393 & 98.946 & 98.514 \\
\hline
\end{tabular}

Fonte: Elaboração própria - Censo escolar 2011, 2012, 2013 e 2014.

O número de matrículas tem diminuído ao longo dos anos. Entre 2011 e 2014 esta redução foi de, aproximadamente, mil alunos. Quanto à infraestrutura escolar, em geral, todas as escolas contavam com água encanada, energia elétrica, esgoto e coleta de lixo periódica. O Quadro 3 sintetiza os dados da infraestrutura das escolas.

Quadro 3: infraestrutura das escolas estaduais - 2014

\begin{tabular}{lccccccc}
\hline \multicolumn{1}{c}{ CIDADES } & SA & SBC & SCS & D & M & RP & RGS \\
\hline Biblioteca & $24 \% 2$ & $03 \%$ & $09 \%$ & $06 \%$ & $27 \%$ & $31 \%$ & $11 \%$ \\
Laboratório de informática & $93 \%$ & $94 \%$ & $100 \%$ & $91 \%$ & $91 \%$ & $100 \%$ & $78 \%$ \\
Laboratório de ciências & $71 \%$ & $55 \%$ & $82 \%$ & $31 \%$ & $33 \%$ & $25 \%$ & $22 \%$ \\
Quadra de esportes & $98 \%$ & $89 \%$ & $100 \%$ & $94 \%$ & $91 \%$ & $100 \%$ & $89 \%$ \\
Sala de leitura & $73 \%$ & $95 \%$ & $91 \%$ & $94 \%$ & $76 \%$ & $50 \%$ & $78 \%$ \\
Sala para a diretoria & $96 \%$ & $91 \%$ & $100 \%$ & $94 \%$ & $97 \%$ & $100 \%$ & $89 \%$ \\
Sala para os professores & $96 \%$ & $95 \%$ & $100 \%$ & $100 \%$ & $94 \%$ & $94 \%$ & $89 \%$ \\
Sala para atendimento especial & $18 \%$ & $25 \%$ & $09 \%$ & $26 \%$ & $27 \%$ & $06 \%$ & $22 \%$ \\
Sala para atendimento especial & $18 \%$ & $25 \%$ & $09 \%$ & $26 \%$ & $27 \%$ & $06 \%$ & $22 \%$ \\
Internet & $93 \%$ & $92 \%$ & $100 \%$ & $94 \%$ & $97 \%$ & $94 \%$ & $89 \%$ \\
Banda larga & $73 \%$ & $83 \%$ & $100 \%$ & $89 \%$ & $82 \%$ & $75 \%$ & $89 \%$ \\
Dependências acessíveis aos & $13 \%$ & $20 \%$ & $27 \%$ & $17 \%$ & $21 \%$ & $19 \%$ & $22 \%$ \\
portadores de deficiência & & & & & & & \\
Sanitários acessíveis aos & $13 \%$ & $28 \%$ & $18 \%$ & $14 \%$ & $33 \%$ & $38 \%$ & $11 \%$ \\
portadores de deficiência & & & & & & & \\
\hline Fonte: Elaboracr̃o própria & & & & & & &
\end{tabular}

Fonte: Elaboração própria - Censo escolar 2014.

\section{Metodologia}

Este estudo avaliou a situação do Ensino Médio das escolas estaduais da região do Grande ABC Paulista, analisando suas taxas de reprovação, de distorção idade-série e de abandono escolar, em uma série histórica com início em 2011 e término em 2014.

2 A porcentagem indicada no Quadro 3 sinaliza o número de escolas que possuíam os componentes da infraestrutura em 2014 (ex: 24\% das escolas possuía biblioteca em Santo André). 
Paralelamente, foi analisado o desempenho das escolas no ENEM e a relação com o nível socioeconômico das instituições.

A região do $\mathrm{ABC}$ foi selecionada, pois se trata de uma das áreas mais ricas do Brasil. Sua população apresentava, em média, mais de nove anos de estudos e o IDH-M médio, era de, aproximadamente, 0,8 . Em média, as escolas possuíam infraestrutura adequada para a aprendizagem dos jovens, de acordo com as indicações realizadas por Soares et al. (2013). Os resultados encontrados neste contexto dificilmente serão localizados em outras regiões brasileiras.

Este estudo utilizou as abordagens metodológicas quantitativa e qualitativa (métodos mistos). A intenção atrelou-se à descrição e à exploração detalhada do fenômeno, inserido em um contexto social e cultural próprio, a partir da análise do meio e da criação de hipóteses. (Johnson e Onwuegbuzie, 2004; Onwuegbuzie e Johnson, 2006). Os métodos mistos apresentam características gerais como o ecletismo metodológico e o pluralismo paradigmático (Tashakkori e Teddlie, 2010, p. 273). Trata-se de realizar a coleta de múltiplos tipos de dados com o propósito de ampliar a compreensão de um problema. Tais métodos utilizam abordagens de pesquisa quantitativa e qualitativa, com a utilização de várias formas de dados relacionadas, entre outras, às análises estatísticas e textuais. Os instrumentos de coleta são variados, abarcando observações, dados censitários e entrevistas para aprofundamento da realidade estudada (Creswell, 2007).

Os dados quantitativos foram coletados no Censo Escolar/Inep nos anos de 2011, 2012, 2013 e 2014 (taxas de reprovação, distorção idade-série e abandono escolar). Posteriormente, foram agrupadas as médias do ENEM das escolas dos sete municípios a partir dos dados do Inep (http://portal.inep.gov.br/basica-levantamentos-acessar) do ano de 2013. O ano de 2013 foi selecionado, pois os dados dos municípios da região do Grande ABC eram representativos. Cada escola teve seu resultado particularizado nas áreas de Ciências Humanas, Ciências da Natureza, Linguagem e Códigos, Matemática e Redação. Juntamente com esses dados, foram coletados outros a partir da Prova Brasil (2013) sobre o nível socioeconômico (NSE) das escolas.

Participaram do estudo 75 escolas $^{3}$ do grande $\mathrm{ABC}$, sendo que 20 delas pertenciam à cidade de Santo André, 31 unidades de ensino eram do município de São Bernardo do Campo, 11 de São Caetano do Sul, sete de Diadema e seis da cidade de Mauá. Trata-se das unidades escolares, em cada município, em que os dados eram representativos (dados do Ideb/Inep de 2013), sendo a taxa de participação no ENEM superior a 50\%.

Os dados advindos das taxas de reprovação, distorção idade-série e abandono escolar foram agrupados em tabelas a partir de 2011. Tal situação teve o intuito de analisar os resultados por meio da identificação das diferenças, regularidades e similaridades. As médias do ENEM das escolas dos municípios também foram incorporadas em tabelas, juntamente com o desvio padrão e o p-valor do teste estatístico.

Foi realizado o teste não paramétrico de Mann-Whitney, por meio da ferramenta estatística IBM-SPSS (versão 23), com o intuito de verificar se as escolas com NSE mais

${ }^{3}$ Ribeirão Pires e Rio Grande da Serra não fizeram parte da amostra, pois a primeira possuía um número inferior a cinco escolas e a segunda somente uma unidade escolar. 
alto apresentavam melhores resultados do que aquelas com o nível mais baixo, ou seja, se as diferenças encontradas não seriam obra do acaso. Trata-se do teste de significância $(\mathrm{p}=$ valor). A abordagem não paramétrica foi utilizada em função de ser mais adequada no caso de distribuições não normais, assim como recomendado por Siegel (1975), como é o caso das distribuições de notas apresentadas nesse estudo (tal verificação foi realizada por meio do teste de Shapiro-Wilk).

Com base nessas análises quantitativas, buscou-se uma avaliação mais detalhada, procurando compreender, baseado na perspectiva dos diretores, as circunstâncias as quais os resultados foram produzidos. Neste caso, trata-se da contextualização dos dados a partir daqueles que conduzem as escolas.

Para a compreensão de tais circunstâncias foram entrevistados quatro diretores de cada município (Santo André, São Bernardo, São Caetano, Diadema e Mauá). A princípio foram selecionados por sorteio, 15 diretores de unidades de ensino de nível socioeconômico mais alto e 15 de nível mais baixo. No entanto, concordaram em participar desta pesquisa seis do primeiro grupo e 14 do segundo, perfazendo um total de 20 profissionais de escolas estaduais de Ensino Médio. As entrevistas eram semiestruturadas, objetivando coletar dados sobre o perfil do diretor (sexo, idade, formação, experiência na profissão, experiência naquela escola e carga de trabalho semanal) e sobre os motivos, na opinião deles, para a ocorrência das altas taxas de reprovação, distorção idade-série e abandono escolar e dos resultados no ENEM. Paralelamente, foram analisados os documentos das escolas, entre eles, o plano de gestão escolar, realizado para um quadriênio, o projeto político pedagógico (PPP) e os planos de aulas dos professores, quando as escolas dispunham dessa documentação.

Esses resultados das análises qualitativas foram interpretados com o suporte da teoria fundamentada, uma abordagem indutiva de pesquisa que possibilita a elaboração de teorias substantivas sobre fenômenos sociais (Corbin e Strauss, 1998). Os dados advindos dos depoimentos, as ideias, as ocorrências e os fenômenos foram, inicialmente, analisados com base em uma investigação temática que possibilitou o agrupamento dos temas mais recorrentes, aqueles que eram centrais e mais significativos e, tal processo, deu origem as categorias.

Os dados foram, a partir dessa codificação e análise, detalhados por meio de uma análise axial, para depois serem filtrados com a utilização de códigos e descritores, possibilitando a compreensão sobre as diferenças, regularidades e similaridades. Um processo que consiste em reduzir e converter os dados para a criação de novas categorias, ampliando, desta forma, o conhecimento sobre os fenômenos.

\section{Resultados}

Os resultados são apresentados inicialmente revelando: (a) as taxas de reprovação, de distorção idade-série e de abandono escolar dos alunos do Ensino Médio das escolas estaduais dos municípios da região do grande $\mathrm{ABC}$ Paulista, e (b) os resultados das escolas no ENEM em todas as áreas (Ciências Humanas, Ciências da Natureza, Linguagem e Códigos, Matemática e Redação) e a relação com o nível socioeconômico das instituições. 


\subsection{Taxas de rendimento, distorção idade-série e abandono escolar}

A Tabela 2 indica as taxas de rendimento, de acordo com dados do Censo Escolar/Inep de 2014 .

Tabela 2. Média de reprovações (\%)

\begin{tabular}{|c|c|c|c|c|c|c|c|c|}
\hline & \multicolumn{4}{|c|}{2014} & \multicolumn{4}{|c|}{2013} \\
\hline & $1^{\circ}$ & $2^{\circ}$ & $3^{\circ}$ & $\mathbf{M}$ & $1^{\circ}$ & $2^{\circ}$ & $3^{\circ}$ & $\mathbf{M}$ \\
\hline Santo André & 22,3 & 15,2 & 7,5 & 15,9 & 23,8 & 14,7 & 7,9 & 16,5 \\
\hline São Bernardo & 22,9 & 15,0 & 8,0 & 16,4 & 25,6 & 15,6 & 9,7 & 18,2 \\
\hline São Caetano & 20,4 & 14,2 & 11,8 & 15,9 & 21,5 & 14,9 & 11,1 & 16,1 \\
\hline Diadema & 15,5 & 10,4 & 5,5 & 11 & 13,7 & 10,4 & 4,4 & 10 \\
\hline Mauá & 15,6 & 10 & 5,5 & 11 & 17,5 & 12,3 & 6,3 & 12,8 \\
\hline Ribeirão Pires & 17,8 & 7,5 & 4,0 & 10,9 & 19,7 & 10,4 & 4,6 & 12,8 \\
\hline Rio Grande & 15,5 & 11 & 3,7 & 11 & 17,6 & 9,3 & 3,0 & 10,8 \\
\hline São Paulo & 16,2 & 11,4 & 5,8 & 11,8 & 17,7 & 12,1 & 6,5 & 12,9 \\
\hline \multirow[t]{3}{*}{ Brasil } & 18 & 11,9 & 7,2 & 13,2 & 17,6 & 11,4 & 7,1 & 12,8 \\
\hline & \multicolumn{4}{|c|}{2012} & \multicolumn{4}{|c|}{2011} \\
\hline & $1^{\circ}$ & $\mathbf{2}^{\circ}$ & $3^{\circ}$ & $\mathbf{M}$ & $1^{\circ}$ & $2^{\circ}$ & $3^{\circ}$ & $\mathbf{M}$ \\
\hline Santo André & 23,4 & 15,2 & 8,0 & 16,7 & 23,5 & 15,4 & 10 & 17,3 \\
\hline São Bernardo & 26 & 18,2 & 11,7 & 19,8 & 29 & 20,8 & 13,1 & 22,1 \\
\hline São Caetano & 23,7 & 19,9 & 17,5 & 20,6 & 27,3 & 20,2 & 12,2 & 20,6 \\
\hline Diadema & 17,1 & 12,6 & 6,6 & 12,7 & 17,3 & 15,1 & 7,7 & 13,9 \\
\hline Mauá & 17,7 & 13,4 & 7,5 & 13,4 & 22,2 & 15,3 & 10,2 & 16,7 \\
\hline Ribeirão Pires & 18 & 11,3 & 4,8 & 12,3 & 25,1 & 15,4 & 9,8 & 17,8 \\
\hline Rio Grande & 20,7 & 10,1 & 8,3 & 13,8 & 23,5 & 15,8 & 8,7 & 17,1 \\
\hline São Paulo & 18,8 & 13,5 & 7,5 & 14 & 20,4 & 14,8 & 8,9 & 15,5 \\
\hline Brasil & 17,7 & 12,1 & 7,5 & 13,2 & 19 & 12,7 & 8,3 & 14,2 \\
\hline
\end{tabular}

Fonte: Elaboração própria.

Avaliando a série histórica em todos os municípios, em São Paulo e também no Brasil, há uma redução nas taxas de reprovação de 2011 para 2014, no entanto essa diminuição, em geral, foi pequena, indicando, em outras coisas, que muitos alunos não avançaram, ampliando, em muitos casos, as taxas de distorção idade-série. Em 2011 e 2012, a maioria das cidades apresentava taxa média de reprovação maior do que o estado de São Paulo e do Brasil, com números superando, em alguns casos, os $17 \%$ e, em outros, os $20 \%$ de reprovação.

Ainda em 2014, Santo André, São Bernardo e São Caetano do Sul possuíam taxas de reprovação mais altas do que a realidade brasileira. Em números absolutos eram, aproximadamente, 4.000, 5.500 e 800 estudantes reprovados, respectivamente. Neste mesmo contexto, as médias mais baixas pertenciam a Ribeirão Pires, Diadema e Mauá. No cenário brasileiro, em 2014, aproximadamente, um milhão de jovens não progrediram em seus estudos, ou seja, foram reprovados (Censo Escolar, 2014).

Em 2014, Santo André, São Bernardo e São Caetano possuíam as piores médias (22,3\%; $22,9 \% ; 20,4 \%$ ), indicando que de cada 100 alunos, mais de 20 eram reprovados. Nessas três cidades, aproximadamente, 5.500 jovens foram reprovados. Nos outros municípios da região, as médias ficaram abaixo de $11 \%$, o que também pode ser considerado elevado.

O problema da reprovação está mais centralizado nos primeiros anos. Em todas as cidades, ele foi maior no início da jornada no Ensino Médio. Apesar de ter havido com o passar dos anos uma diminuição nas taxas de reprovação, ela ainda é muito elevada. No 
ano de 2011, em algumas cidades os números giravam em torno de 25\% (Santo André, Mauá, Ribeirão Pires, Rio Grande) e em outras (São Bernardo e São Caetano) chegaram, aproximadamente, aos $30 \%$.

Em 2014, todas as cidades, incluindo o estado de São Paulo e o Brasil, estavam com taxas de reprovação acima de $15 \%$ nos primeiros anos do Ensino Médio e, alguns municípios, acima dos 20\% (Santo André, São Bernardo e São Caetano). Esses municípios possuíam taxas mais altas do que a média brasileira.

Em relação à distorção idade-série, a Tabela 3 sintetiza os dados.

Tabela 3. Distorção idade-série (\%)

\begin{tabular}{|c|c|c|c|c|c|c|c|c|c|c|c|c|c|c|c|c|}
\hline & \multicolumn{4}{|c|}{2014} & \multicolumn{4}{|c|}{2013} & \multicolumn{4}{|c|}{2012} & \multicolumn{4}{|c|}{2011} \\
\hline & $1^{\circ}$ & $2^{\circ}$ & $3^{\circ}$ & $\mathbf{T}$ & $1^{\circ}$ & $2^{\circ}$ & $3^{\circ}$ & $\mathbf{T}$ & $1^{\circ}$ & $2^{\circ}$ & $3^{\circ}$ & $\mathbf{T}$ & $1^{\circ}$ & $2^{\circ}$ & $3^{\circ}$ & $\mathrm{T}$ \\
\hline $\begin{array}{l}\text { Santo } \\
\text { André }\end{array}$ & 20 & 17 & 12 & 17 & 22 & 18 & 13 & 18 & 22 & 18 & 12 & 18 & 23 & 19 & 16 & 20 \\
\hline $\begin{array}{l}\text { São } \\
\text { Bernardo } \\
\text { do Campo }\end{array}$ & 23 & 17 & 12 & 18 & 23 & 18 & 13 & 19 & 23 & 19 & 15 & 20 & 25 & 21 & 17 & 22 \\
\hline $\begin{array}{l}\text { São } \\
\text { Caetano do } \\
\text { Sul }\end{array}$ & 26 & 21 & 18 & 22 & 25 & 22 & 19 & 22 & 28 & 23 & 21 & 24 & 27 & 22 & 18 & 23 \\
\hline Diadema & 20 & 17 & 13 & 17 & 21 & 19 & 15 & 19 & 22 & 21 & 18 & 20 & 22 & 20 & 16 & 20 \\
\hline Mauá & 16 & 12 & 10 & 13 & 16 & 15 & 11 & 14 & 19 & 17 & 12 & 17 & 22 & 17 & 14 & 18 \\
\hline $\begin{array}{l}\text { Ribeirão } \\
\text { Pires }\end{array}$ & 16 & 11 & 7,0 & 12 & 17 & 12 & 7 & 13 & 18 & 13 & 8 & 14 & 16 & 13 & 9 & 13 \\
\hline $\begin{array}{l}\text { Rio Grande } \\
\text { da Serra }\end{array}$ & 18 & 14 & 8 & 14 & 18 & 13 & 8 & 14 & 19 & 14 & 9 & 15 & 23 & 18 & 16 & 20 \\
\hline São Paulo & 19 & 16 & 12 & 16 & 21 & 17 & 13 & 17 & 21 & 18 & 14 & 18 & 22 & 19 & 15 & 19 \\
\hline Brasil & 35 & 30 & 27 & 32 & 37 & 31 & 29 & 33 & 39 & 33 & 31 & 35 & 40 & 34 & 33 & 37 \\
\hline
\end{tabular}

Fonte: Elaboração própria.

Na Tabela 3, a coluna "T" (Total) indica que de cada 100 alunos um percentual de jovens estava com atraso escolar de dois ou mais anos. Santo André, nos anos de 2011, 2012, 2013 e 2014 possuía, respectivamente, 20, 18, 18 e 17 jovens em cada 100 com atraso escolar. Em geral, analisando a série histórica em todos os municípios, incluindo do estado de São Paulo e os dados do Brasil, houve redução nos índices de distorção idadesérie. A cidade de Rio Grande da Serra foi aquela em que a diminuição foi maior ao longo dos anos.

No entanto, neste contexto, a média brasileira de 2014, apesar da redução, ainda é muito alta e indica uma realidade que necessita de intervenções urgentes, pois a cada 100 alunos 32 estavam com atraso escolar de dois anos ou mais (Censo Escolar, 2014). Os municípios de Mauá e Ribeirão Pires foram aqueles que ao longo dos anos analisados possuíam as médias mais baixas de distorção.

Assim como nos dados de reprovação, as maiores taxas de distorção idade-série estavam mais localizadas nos primeiros anos. Ainda em 2014, todos os municípios apresentaram taxas superiores a 15\%, apesar de uma redução ao longo dos anos a partir de 2011. Os dados mostraram ainda que a maior média, a brasileira, chegou aos 35\% no ano de 2014 .

Quanto ao abandono escolar deve-se, inicialmente, sinalizar que se trata de um fenômeno caracterizado quando o estudante deixa de frequentar a escola. A Tabela 4 mostra os resultados da região do Grande $\mathrm{ABC}$. 
Tabela 4. Abandono escolar (\%)

\begin{tabular}{lcccccccc}
\hline & \multicolumn{9}{c}{$\mathbf{2 0 1 4}$} & \multicolumn{4}{c}{$\mathbf{2 0 1 3}$} \\
& $\mathbf{1}^{\circ}$ & $\mathbf{2}^{\circ}$ & $\mathbf{3}^{\circ}$ & $\mathbf{M}$ & $\mathbf{1}^{\circ}$ & $\mathbf{2}^{\circ}$ & $\mathbf{3}^{\circ}$ & $\mathbf{M}$ \\
\hline Santo André & 5,8 & 4,6 & 3,2 & 4,7 & 7,7 & 6,2 & 3,8 & 6,2 \\
São Bernardo do Campo & 5,6 & 4,1 & 3,1 & 4,5 & 6,6 & 4,7 & 3,3 & 5,1 \\
São Caetano do Sul & 4,4 & 3,5 & 3,0 & 3,7 & 6,4 & 5,4 & 4,1 & 5,4 \\
Diadema & 4,2 & 5,1 & 2,9 & 4,1 & 6,0 & 6,4 & 4,3 & 5,7 \\
Mauá & 3,7 & 2,6 & 3,0 & 3,1 & 5,2 & 4,6 & 3,0 & 4,4 \\
Ribeirão Pires & 3,1 & 2,1 & 1,1 & 2,3 & 5,9 & 3,4 & 1,1 & 3,8 \\
Rio Grande da Serra & 6,1 & 3,6 & 2,7 & 4,4 & 9,4 & 5,2 & 5,0 & 6,9 \\
São Paulo & 6,0 & 4,9 & 3,5 & 5,0 & 6,8 & 5,7 & 3,9 & 5,7 \\
Brasil & 10,8 & 8,4 & 6,1 & 8,8 & 11,5 & 8,7 & 6,5 & 9,3 \\
\hline
\end{tabular}

\begin{tabular}{lcccccccc}
\hline & \multicolumn{4}{c}{$\mathbf{2 0 1 2}$} & \multicolumn{5}{c}{$\mathbf{2 0 1 1}$} \\
\cline { 2 - 9 } & $\mathbf{1}^{\circ}$ & $\mathbf{2}^{\circ}$ & $\mathbf{3}^{\circ}$ & $\mathbf{M}$ & $\mathbf{1}^{\circ}$ & $\mathbf{2}^{\circ}$ & $\mathbf{3}^{\circ}$ & $\mathbf{M}$ \\
\hline Santo André & 8,0 & 6,8 & 5,8 & 7,0 & 8,4 & 6,9 & 5,3 & 7,1 \\
São Bernardo do Campo & 5,6 & 5,1 & 4,3 & 5,1 & 5,1 & 4,2 & 3,6 & 4,4 \\
São Caetano do Sul & 4,1 & 3,6 & 2,4 & 3,4 & 3,6 & 4,2 & 2,3 & 3,4 \\
Diadema & 7,8 & 7,6 & 5,1 & 7,0 & 5,9 & 4,7 & 4,5 & 5,1 \\
Mauá & 5,5 & 4,1 & 2,5 & 4,2 & 4,1 & 2,9 & 2,5 & 3,3 \\
Ribeirão Pires & 5,4 & 3,7 & 2,9 & 4,2 & 3,5 & 2,3 & 2,0 & 2,7 \\
Rio Grande da Serra & 6,4 & 7,0 & 4,7 & 6,2 & 5,5 & 5,9 & 5,2 & 5,5 \\
São Paulo & 6,4 & 5,5 & 3,8 & 5,4 & 6,2 & 5,2 & 3,9 & 5,2 \\
Brasil & 13,1 & 9,8 & 7,4 & 10,5 & 13,4 & 10,1 & 8,0 & 10,9 \\
\hline
\end{tabular}

Fonte: Elaboração própria.

As taxas de abandono escolar na região do Grande ABC Paulista, escolas estaduais, são muito elevadas. No entanto, ainda um pouco abaixo do estado de São Paulo (5,0\%) e do Brasil (8,8\%). De fato, os dados brasileiros mostraram uma dura realidade em relação a este fenômeno. Na análise histórica, 2011 até 2014, é possível observar que os municípios de São Bernardo e de São Caetano do Sul foram aqueles que não atingiram uma redução ao longo dos anos e até aumentaram seus níveis.

O abandono escolar seguiu o fenômeno da reprovação e da distorção idade-série, sendo maior nos primeiros anos do Ensino Médio. Os municípios de São Bernardo do Campo e São Caetano do Sul se constituíram naquelas cidades em que as taxas de abandono, de 2011 até 2014, aumentaram.

No Brasil, em 2014, o número absoluto de alunos que deixou a escola, de acordo com o Censo Escolar, foi de, aproximadamente, 611 mil estudantes. Realizando o cruzamento entre a categoria abandono escolar e a de dias letivos (200 dias), conclui-se que a cada 30 segundos um aluno brasileiro do Ensino Médio abandonou estudos. Uma realidade difícil de ser compreendida nos dias atuais. A situação na região do Grande ABC foi, em alguns casos, ainda mais trágica, já que se trata de uma área de nível socioeconômico mais elevado. Em Santo André, 2014, o número absoluto de alunos que deixou a escola foi de 1.099 jovens, sinalizando que a cada 4 horas e meia um estudante abandonou a escola. Em São Bernardo, um jovem a cada três horas e meia deixou os estudos. Em São Caetano, os dados mostraram que, aproximadamente, um por dia. Em Diadema, um a cada seis horas. Na cidade de Mauá, um jovem a cada oito horas e em Ribeirão Pires e Rio Grande da Serra um a cada dois dias. Uma leitura da região do grande ABC indicou que, aproximadamente, a cada hora um jovem do Ensino Médio abandonou a escola. 


\subsection{Dados das escolas no ENEM e a relação com o nível socioeconômico dos jovens.}

Participaram deste estudo da região do grande $\mathrm{ABC}$ escolas pertencentes à esfera estadual. Trata-se das unidades escolares em que os dados eram representativos, sendo a taxa de participação no Exame Nacional do Ensino Médio superior a 50\%. A Tabela 5 sintetiza os resultados dos municípios.

Em todos os municípios, e na região do grande $\mathrm{ABC}$ como um todo, os dados revelaram que as menores médias foram as provenientes da área de Ciências da Natureza. Santo André: 465,8 pontos para as escolas de nível socioeconômico mais baixo e 487,4 pontos para aquelas com NSE mais alto, São Bernardo 458,9 e 475,7, São Caetano 451,5 e 487,5, Diadema 447,8 e 474,9 e Mauá 459,3 e 464,8. As notas mais altas, na mesma ordem de cidades, foram em Redação (507,2 e 536,9), Matemática (504,3 e 523,1), Matemática (497,9 e 561,0), Redação $(489,1$ e 538,6) e Matemática (493,2 e 518,7).

Na cidade de Santo André, os dados indicaram que as escolas com nível socioeconômico mais baixo apresentaram médias mais baixas em todas as áreas (Ciências Humanas, Ciências da Natureza, Linguagem e Códigos, Matemática e Redação) do que aquelas com NSE mais alto. Em Matemática e Redação essas diferenças foram maiores (23,5 e 29,7 pontos). As diferenças foram estatisticamente significativas nas áreas de Ciências da Natureza, Matemática e Redação, indicando que nessas áreas o NSE interferiu nos resultados.

No município de São Bernardo, escolas com NSE mais baixo também obtiveram médias mais baixas em todas as áreas do que aquelas com nível socioeconômico mais alto. A área de Matemática apresentou a maior diferença (18,8 pontos). Os resultados mostraram que essas diferenças foram estatisticamente significativas em todas as áreas, exceto em Redação. Tal situação sinaliza que o nível socioeconômico foi determinante no desempenho dos alunos no ENEM.

Em São Caetano do Sul, os dados revelaram que as escolas com nível socioeconômico mais baixo atingiram médias mais baixas em todas as áreas em relação àquelas com NSE mais alto. As áreas de Redação e Matemática apresentaram as maiores diferenças, respectivamente: 79,7 e 63,1 pontos. As diferenças entre as médias foram estatisticamente significativas em todas as áreas, sinalizado que o nível socioeconômico interferiu nos resultados.

Nas cidades de Diadema e Mauá, as escolas com NSE mais baixo também obtiveram médias menores em todas as áreas em relação àquelas com NSE mais alto. No entanto, diferente dos outros municípios, esses dados, em função do reduzido número de instituições na amostra, não permitiram testes estatísticos.

Na Região do Grande ABC, as análises sinalizaram que as escolas com NSE mais alto apresentaram médias mais altas em todas as áreas. As maiores diferenças foram situadas nas áreas de Redação (36 pontos) e Matemática (29,7 pontos). Os resultados encontrados revelaram que existem diferenças estatisticamente significativas em todas as áreas, indicando que, nesta região, o NSE interferiu no desempenho dos alunos. Ele foi determinante no resultado, ou seja, aqueles que eram mais favorecidos, das classes sociais mais abastadas, obtiveram melhores desempenhos em relação aos seus colegas mais pobres. 
Tabela 5. Municípios, áreas do ENEM e pontuações das escolas

\begin{tabular}{|c|c|c|c|c|c|c|c|}
\hline & & \multicolumn{2}{|c|}{$\begin{array}{l}\text { CIÊNCIAS } \\
\text { HuMANAS }\end{array}$} & \multicolumn{2}{|c|}{$\begin{array}{l}\text { CIÊNCIAS DA } \\
\text { NATUREZA }\end{array}$} & \multicolumn{2}{|c|}{$\begin{array}{l}\text { LINGUAGENS E } \\
\text { CódIGOS }\end{array}$} \\
\hline & & NSEB & NSEA & NSEB & NSEA & NSEB & NSEA \\
\hline \multirow{3}{*}{ Santo André } & Média & 506,9 & 519,1 & 465,8 & 487,4 & 494,9 & $\overline{508,6}$ \\
\hline & D. P. & 7,80 & 31,6 & 10,1 & 17,5 & 10,3 & 27,5 \\
\hline & Sig. & \multicolumn{2}{|c|}{, 315} & \multicolumn{2}{|c|}{, 046} & \multicolumn{2}{|c|}{, 247} \\
\hline \multirow{3}{*}{ São Bernardo } & Média. & 498,5 & 515,3 & 458,9 & 475,7 & 495,9 & 508,8 \\
\hline & D. P. & 14,2 & 24,7 & 10,1 & 25,8 & 13,4 & 22,9 \\
\hline & Sig. & \multicolumn{2}{|c|}{0,009} & \multicolumn{2}{|c|}{0,019} & \multicolumn{2}{|c|}{0,078} \\
\hline \multirow{3}{*}{ São Caetano } & Média & 487,9 & 538,5 & 451,5 & 487,5 & 479,8 & 527,7 \\
\hline & D. P. & 7,20 & 33,7 & 8,50 & 34,9 & 6,89 & 27,0 \\
\hline & Sig. & \multicolumn{2}{|c|}{0,004} & \multicolumn{2}{|c|}{0,009} & \multicolumn{2}{|c|}{0,004} \\
\hline \multirow{3}{*}{ Diadema } & Média & 493,0 & 529,5 & 447,8 & 474,9 & 483,1 & 511,1 \\
\hline & D. P. & \multirow{2}{*}{\multicolumn{2}{|c|}{56,0}} & 10,0 & 44,5 & 5,26 & 47,2 \\
\hline & Sig. & & & \multicolumn{2}{|c|}{-} & \multicolumn{2}{|c|}{-} \\
\hline \multirow{3}{*}{ Mauá } & Média & 490,2 & 511,8 & 459,3 & 464,8 & 481,1 & 500,1 \\
\hline & D. P. & 15,4 & 2,77 & 19,9 & 9,08 & 20,5 & 7,86 \\
\hline & Sig. & \multicolumn{2}{|l|}{$10,+$} & \multicolumn{2}{|c|}{-} & \multicolumn{2}{|c|}{-} \\
\hline \multirow{3}{*}{ Região do ABC } & Média & 497,9 & 521 & 457,4 & 478,4 & 490,3 & 511,9 \\
\hline & D. P. & 12,6 & 29,8 & 11,6 & 26,7 & 13,2 & 25,5 \\
\hline & Sig. & \multicolumn{2}{|c|}{$<0,01$} & \multicolumn{2}{|c|}{$<0,01$} & \multicolumn{2}{|c|}{$<0,01$} \\
\hline
\end{tabular}

\begin{tabular}{|c|c|c|c|c|c|}
\hline & & \multicolumn{2}{|c|}{ MATEMÁTICA } & \multicolumn{2}{|c|}{ REDAÇÃO } \\
\hline & & NSEB & NSEA & NSEB & NSEA \\
\hline \multirow{3}{*}{ Santo André } & Média & 502,0 & 525,5 & 507,2 & 536,9 \\
\hline & D. P. & 10,7 & 38,7 & 26,2 & 41,9 \\
\hline & Sig. & \multicolumn{2}{|c|}{0,015} & \multicolumn{2}{|c|}{0,029} \\
\hline \multirow{3}{*}{ São Bernardo } & Média. & 504,3 & 523,1 & 514,0 & 530,2 \\
\hline & D. P. & 8,84 & 33,6 & 26,5 & 42,0 \\
\hline & Sig. & \multicolumn{2}{|c|}{0,021} & \multicolumn{2}{|c|}{0,299} \\
\hline \multirow{3}{*}{ São Caetano } & Média & 497,9 & 561,0 & 470,5 & 550,2 \\
\hline & D. P. & 11,9 & 45,7 & 19,8 & 40,2 \\
\hline & Sig. & \multicolumn{2}{|c|}{0,004} & \multicolumn{2}{|c|}{0,004} \\
\hline \multirow{3}{*}{ Diadema } & Média & 485,7 & 525,0 & 489,1 & 538,6 \\
\hline & D. P. & 13,2 & 44,5 & 8,58 & 49,5 \\
\hline & Sig. & \multicolumn{2}{|c|}{-} & \multicolumn{2}{|c|}{-} \\
\hline \multirow{3}{*}{ Mauá } & Média & 493,2 & 518,7 & 468,5 & 516,5 \\
\hline & D. P. & 3,71 & 12,8 & 16,7 & 8,25 \\
\hline & Sig. & \multicolumn{2}{|c|}{-} & \multicolumn{2}{|c|}{-} \\
\hline \multirow{3}{*}{ Região do ABC } & Média & 499,9 & 529,6 & 499,3 & 535,3 \\
\hline & D. P. & 11,1 & 37,6 & 28,3 & 39,4 \\
\hline & Sig. & \multicolumn{2}{|c|}{$<0,01$} & \multicolumn{2}{|c|}{$<0,01$} \\
\hline
\end{tabular}

* NSEB ${ }^{4}$ : Nível Socioeconômico Baixo. NSEA: Nível Socioeconômico Alto.

Fonte: Elaboração própria.

${ }^{4}$ Os dados sobre o nível socioeconômico das escolas foram coletados a partir da Prova Brasil de 2013. 


\section{A contextualização dos resultados: Dados dos diretores escolares}

A contextualização dos dados encontrados foi realizada a partir de entrevistas realizadas com diretores de escolas de Ensino Médio da região do grande ABC Paulista e por meio de uma análise documental. Esses profissionais apontaram vários pontos como fatores determinantes para as altas taxas de reprovação, de distorção idade-série, de abandono escolar e para os resultados das instituições no ENEM. Os dados permitiram uma categorização, agrupando indicativos que responsabilizavam os alunos, às famílias, os professores e à secretaria de educação.

No primeiro caso, em relação à responsabilização dos alunos, foi indicado o elevado número de faltas semanais dos jovens (alto índice de absenteísmo):

Todas as semanas temos inúmeras faltas dos alunos...tem aluno que nem aparece na escola. (Diretor, 09)

Alguns alunos não comparecem na escola, não justificam suas faltas. Aí num momento ele aparece. Quando aparece não faz nada e de repente some de novo. (Diretor, 07)

A falta de interesse e de motivação com os estudos, traduzida pelo número de atrasos nas aulas, desinteresse com os conteúdos escolares:

Quando o aluno percebe que não está indo bem, ele começa a faltar ainda mais e quando pega o boletim e vê que já está praticamente reprovado ele desiste, ele some da escola. (Diretor, 18)

Desprezo com as tarefas de casa:

Hoje em dia é difícil um aluno de ensino médio que faz a lição de casa. Somente um pequeno grupo, mas pequeno mesmo. A coisa é assim, se um aluno faz, os outros copiam, sabe, é sempre assim. (Diretor, 13)

A ausência de postura do jovem, traduzida pelo desrespeito com os professores e, algumas vezes, com os próprios colegas. Situações revestidas por ameaças, ofensas ou agressões ao professor, funcionário ou a outro aluno e pela insistência do uso do celular em sala de aula:

Você pede para desligar o celular e eles colocam no modo de vibrar, escondem, e não desligam... às vezes sabe ficam ouvindo música em sala de aula e outras vezes trocando mensagens, é um total desrespeito com os professores. (Diretor, 02 )

A necessidade de trabalhar, traduzida pela demanda social e econômica da família:

Muitos jovens nesta fase precisam trabalhar para ajudar as famílias e desta forma eles deixam a escola. (Diretor, 12)

Neste processo, há que se destacar que para quase metade dos diretores há um ciclo para muitos estudantes que se inicia com a reprovação, que acaba provocando a distorção idade-série e, por fim, a evasão do jovem.

No segundo grupo, os diretores responsabilizavam às famílias. A grande questão situada por eles estava relacionada à falta de participação dos familiares nas atividades escolares dos filhos. Todos os diretores registraram descaso dos pais com a educação escolar dos filhos:

Os pais não participam da vida escolar de seus filhos e se participam ou quando é sempre para criticar a escola ou o diretor ou o professor. (Diretor, 09) 
Tudo agora é na escola. Nós fazemos o que os pais deveriam fazer. Daqui a pouco o que será que teremos de fazer, quem sabe, dar nota para todos. (Diretor 13)

Em relação aos professores, vários depoimentos surgiram. O Tabla 6, sintetiza os dados.

Tabla 6. Depoimentos dos diretores sobre os professores

\begin{tabular}{|c|c|c|c|}
\hline AFIRMAÇÃO & FREQ. & AFIRMAÇÃO & FREQ. \\
\hline $\begin{array}{l}\text { Alto índice de faltas dos } \\
\text { professores }\end{array}$ & 14 & Aulas repetitivas e entediantes & 09 \\
\hline $\begin{array}{l}\text { Desinteresse pela } \\
\text { aprendizagem do aluno }\end{array}$ & 11 & Falta de interesse pelo aluno & 09 \\
\hline $\begin{array}{l}\text { Falta de participação nas } \\
\text { atividades (Reuniões de pais, } \\
\text { conselho de classe) }\end{array}$ & 11 & $\begin{array}{l}\text { Baixo grau de colaboração ou trabalho em } \\
\text { equipe }\end{array}$ & 07 \\
\hline $\begin{array}{l}\text { Não cumprimento dos } \\
\text { conteúdos propostos no } \\
\text { planejamento }\end{array}$ & 10 & Falta de pontualidade em sala de aula & 06 \\
\hline $\begin{array}{l}\text { Falta de estratégias para } \\
\text { motivar os estudantes }\end{array}$ & 10 & $\begin{array}{l}\text { Falta de cuidado com a documentação do } \\
\text { aluno, sobretudo os registros no diário de } \\
\text { classe e a construção de relatórios }\end{array}$ & 05 \\
\hline Falta de formação do professor & 10 & $\begin{array}{l}\text { Falta de estratégias para lidar com a } \\
\text { disciplina em sala de aula }\end{array}$ & 05 \\
\hline
\end{tabular}

Fonte: Elaboração própria.

Entre as frequências mais altas, acima de dez, estão questões delicadas em relação às escolas brasileiras: o absenteísmo do professor, a falta de participação docente na escola, a formação do professor, entre outros.

Quanto à secretaria de educação, os argumentos captados nas entrevistas mostraram que acontecem duas situações. A primeira se relaciona à quantidade de exigências e cobranças em relação ao rendimento dos alunos no IDEB ou no ENEM. Os diretores sinalizaram que a cada momento tem uma coisa nova para ser realizada. A segunda está atrelada à falta apoio para as escolas, relacionadas, sobretudo à necessidade de professores substitutos ou, às vezes, de infraestrutura básica, como tinta para impressora e papel, ou ainda à questão, em alguns casos, das salas de aulas lotadas.

Por fim, a partir da análise documental e também das entrevistas, surgiram três fatores que podem ser agregados à contextualização dos dados. Nas escolas verificou-se a: a) Ausência de projetos para lidar com o absenteísmo dos alunos e dos professores. As instituições não tinham estratégias para enfrentar esses problemas e, em algumas delas, tal situação não era nem conhecida e nem prioridade. b) Falta de programas de monitoramento dos alunos. Apesar da preocupação das equipes gestoras no acompanhamento dos alunos, com procedimentos assentados, sobretudo sobre a parte cognitiva do jovem (acompanhamento da nota e da disciplina escolar), havia carência de entendimento quanto ao monitoramento, periodicidade e formas de atuação. c) Falta de formação do diretor. Ausência de conhecimento sobre as políticas educacionais, sobre a gestão do planejamento, de pessoas e de resultados, sobre as culturas juvenis, entre outras.

\section{Discussão dos resultados}

Uma das primeiras sinalizações deste estudo relaciona-se ao fato de a região do grande ABC apresentar médias de reprovação elevadas e mais concentradas nos primeiros anos 
do Ensino Médio. Neste processo, a cidade de São Caetano possuía os piores resultados entre as escolas estaduais dos sete municípios. A distorção idade-série também era elevada e centralizada nos primeiros anos, sendo São Caetano e Diadema os municípios com os índices mais altos.

As taxas de abandono escolar na região também eram muito elevadas, apesar de estarem abaixo do estado de São Paulo e do Brasil. As cidades de Santo André e Rio Grande da Serra possuíam os piores resultados. Os dados deste estudo sinalizaram uma situação crítica quanto à evasão escolar da região do grande $\mathrm{ABC}$ Paulista. De fato, o dado mais significativo encontrado neste estudo atrela-se à questão de que a cada hora um jovem do Ensino Médio abandona a escola.

Situação similar havia sido encontrada, recentemente, em um estudo no Rio Grande do Sul (Salva, Ramos e Ramos, 2016), revelando altas taxas de reprovação, de distorção idade-série e de abandono escolar, localizadas mais no primeiro ano do Ensino Médio, mostrando que parece não se tratar de um fenômeno local da região do grande $\mathrm{ABC}$.

As consequências desse atraso escolar afetam o prosseguimento dos jovens rumo às universidades. Neste sentido, muito deles que abandonaram os estudos, quando retornam o fazem por meio das ações e das inciativas da Educação de Jovens e Adultos, realizando um tipo de educação que há ainda gera muita controvérsia no Brasil.

Neste presente estudo, a compreensão deste cenário empobrecido sinalizou uma demanda relacionada à responsabilização dos alunos, das famílias, dos professores e da secretaria de educação. No primeiro caso, foram indicados como fatores relevantes o elevado índice de absenteísmo dos jovens, a falta de motivação com a escola e com os estudos, a falta de postura do estudante e a necessidade de trabalhar. No segundo, foi citada a ausência de participação dos familiares nas atividades escolares dos filhos. No terceiro, foram sinalizados o alto índice de absenteísmo, o desinteresse pela aprendizagem do aluno, a falta de participação das atividades da escola, a ausência de estratégias para motivar os estudantes, a formação precária do professor, as aulas repetitivas e entediantes, entre outros. Por fim, quanto à secretaria de educação, os argumentos se atrelaram às altas exigências, à falta de apoio e à criação de salas de aulas superlotadas. Aliadas a essas categorias, as instituições careciam de projetos para lidar com o absenteísmo dos alunos e dos professores, de programas de monitoramento dos alunos, de conhecimento sobre as políticas educacionais, sobre a gestão do planejamento, de pessoas, de resultados e estratégias para lidar com as culturas juvenis, entre outras.

Observa-se que não há uma única causa que determine a reprovação, a distorção e o abandono escolar e os baixos resultados no ENEM, na opinião dos diretores. Neste caso, existe uma multiplicidade de fatores que, possivelmente, devem atuar juntos e em graus diferentes sobre os diversos os fenômenos. Tal situação indica que as soluções para o enfrentamento de tal crise também deverão ser baseadas em múltiplas intervenções no nível do sistema, da escola, do professor, da família e do aluno.

As causas do afastamento dos jovens da escola encontradas por Salva, Ramos e Ramos (2016), apresentam similaridade com as localizadas neste presente estudo: necessidade do jovem trabalhar; ausência de diálogo com a escola; conteúdos escolares distantes da realidade dos jovens; descaso dos gestores; metodologias inadequadas e gravidez precoce, entre outros. Néri (2009) mostrou que entre as razões mais indicadas pelos 
jovens de 15 a 17 anos para não frequentar a escola estavam a necessidade de trabalhar e a falta de motivação. Todos esses aspectos são relacionados à questão social e à realidade escolar. Podemos compreender que há alguma semelhança entre o que os alunos indicaram como justificativas para abandonar a escola e as sinalizações realizadas pelos diretores neste estudo.

A reprovação está fortemente relacionada à distorção idade-série e à evasão escolar. Para muitos alunos do grande $\mathrm{ABC}$ trata-se de um ciclo perverso que tem início na reprovação e termina na evasão escolar. Krawczyk (2013) afirma que muitas pesquisas revelaram que a evasão no EM acontece, em geral, quando o jovem é informado de seus resultados escolares, mesmo que parciais, e esses indicam uma possível reprovação.

Em outro estudo Krawczyk (2011, p. 756) afirma que a evasão que persiste nos últimos anos, depois da política de expansão do EM, "aponta para uma crise de legitimidade da escola, que resulta não apenas da crise econômica ou do declínio da utilidade social dos diplomas, mas também da falta de outras motivações para os alunos continuarem estudando".

A discussão em relação ao ENEM mostra que os resultados deste exame não foram adequados em nenhuma das áreas, no entanto eles foram piores na área de Ciências da Natureza. Tais resultados vão ao encontro dos dados encontrados por Viggiano e Mattos (2013) onde, entre as médias de todas as áreas do ENEM, a mais inferior situouse em Ciências da Natureza. Os autores mostraram que a média nacional não foi superior aos 488 pontos.

Um dos motivos que explica tal fato reside na questão de que no Ensino Médio existe, em geral, uma carência de professores com formação adequada (Brasil: 41\%) e, em particular, nas disciplinas relacionadas às ciências exatas. De acordo com dados da Sinopse Estatística da Educação Básica, no ano de 2010, somente 20\% dos docentes com formação superior que atuavam no EM possuíam formação específica em relação às áreas de Ciências, Física ou Matemática. Dados do Observatório da Educação do grande ABC revelaram, a partir do Censo Escolar de 2014, que há um grande número de docentes sem licenciatura na disciplina que atuam. Em geral, em números aproximados, Santo André possuía 36\% de seus professores sem certificação apropriada, São Bernardo 30\%, São Caetano 32\%, Diadema 36\%, Mauá 32\%, Ribeirão Pires 42\%, Rio Grande da Serra 48\%. Especificamente, nas áreas de Química e Física, os mesmos municípios apresentaram, respectivamente: $29 \%$ e $76 \%, 15 \%$ e $68 \%, 22 \%$ e $55 \%, 25 \%$ e $84 \%, 20 \%$ e $60 \%, 28 \%$ e $61 \%, 78 \%$ e $47 \%$. Nessas mesmas duas áreas no Brasil faltam $40 \%$ e $60 \%$ de docentes com credencias adequadas para atuar no EM. Tal problema, entre outras coisas, está relacionado a falta de atratividade na carreira.

O presente estudo mostrou que as diferenças entre as áreas foram maiores em Redação, em alguns casos superando 65 pontos, e em Matemática, em algumas cidades, superior a 63 pontos. Em todas as áreas, as maiores desigualdades foram encontradas na cidade de São Caetano do Sul (CH=50,6 pontos, $\mathrm{CN}=36, \mathrm{LC}=47,9, \mathrm{M}=63,1$ e $\mathrm{RE}=79,7)$. Uma das explicações para tal fato pode estar atrelada às altas desigualdades sociais encontradas no município (índice Gini maior da região).

Quanto ao nível socioeconômico e os resultados, em Santo André as escolas com nível socioeconômico mais baixo apresentaram médias mais baixas em todas as áreas, sendo 
que as diferenças foram estatisticamente significativas nas áreas de Ciências da Natureza, Matemática e Redação, indicando que realmente nessas NSE interferiu nos resultados. Em São Bernardo, o resultado foi bem parecido. A diferença só não foi estatisticamente significativa em Redação. Na cidade de São Caetano, em todas as áreas foram encontradas diferenças estatisticamente significativas, sinalizado a interferência do NSE nos resultados dos alunos. Por fim, nos municípios de Diadema e Mauá, as médias das escolas com menor NSE também foram mais baixas em todas as áreas.

A análise da região do grande $\mathrm{ABC}$ revelou que as escolas com NSE mais baixo apresentaram médias mais inferiores em todas as áreas, sendo notada a existência de diferenças estatisticamente significativas, indicando a interferência do nível socioeconômico nos resultados. Tal situação indica que aqueles jovens mais favorecidos socioeconomicamente obtiveram melhores desempenhos em relação aos seus colegas mais pobres. Sinalização similar foi encontrada por Travitzki (2013), que analisou dados do ENEM 2009 e 2010. Este autor mostrou que o nível socioeconômico explicava 80\% das médias das escolas. No entanto, os dados deste presente estudo são mais representativos, pois a taxa de participação no ENEM foi superior a $50 \%$.

\section{Considerações finais}

Esta pesquisa revelou e analisou a situação do Ensino Médio das escolas estaduais de uma das regiões mais importantes do Brasil, o grande ABC Paulista, com o foco associado às taxas de reprovação, de distorção idade-série, de abandono escolar e ao desempenho das escolas no Exame Nacional do Ensino Médio.

Este presente estudo tem como premissa a questão de que os resultados divulgados pelo Inep, de caráter quantitativo, apresentam pouco sentido se não forem contextualizados e analisados em um quadro mais amplo, que dialogue com os fatores condicionantes de tais resultados.

Trata-se de um estudo que indica e adverte que mesmo em uma das regiões mais ricas do Brasil, as médias de reprovação, de distorção idade-série e de abandono escolar, apesar de queda de 2011 para 2014, ainda são muito elevadas e concentradas no primeiro ano do Ensino Médio. As causas encontradas apontam para múltiplos fatores, envolvendo alunos, famílias, professores e gestores escolares.

Há ainda uma questão muito mais alarmante atrelada ao fato de que a cada hora um jovem deste segmento abandona a escola. Um achado preocupante para as autoridades políticas, educacionais, gestores, professores, pais e comunidade, que indica a necessidade urgente de políticas educacionais no nível do sistema, da escola, do professor e da sala de aula.

Destaca-se, em relação ao ENEM, que as médias mais inferiores se situaram na área de Ciências da Natureza. Em todas as cidades analisadas o nível socioeconômico interferiu nos resultados. Tal situação nos autoriza a concluir que as condições socioeconômicas e culturais das famílias explicam, em grande medida, as competências e as aquisições realizadas pelos alunos (desempenho). No entanto, é interessante destacar que mesmo em uma das regiões mais ricas as desigualdades sociais continuam se transformado em 
desigualdades escolares e que a atuação das escolas, o trabalho escolar, não tem atenuado esta realidade.

As conclusões finais deste estudo deveriam ser tomadas com seriedade pelas autoridades políticas e educacionais, incluindo gestores e professores, da região do grande ABC. Elas indicam uma demanda que exige iniciativas e ações urgentes a serem realizadas na região e nos municípios.

\section{Referências}

Bizzo, N., Gouw, A. M. S., Garcia, P. S., Tolentino-Neto, L. C. e Monteiro, P. H. N. (2013). Incontext items in a nationwide examination: Which knowledge and skills are actually assessed? Proceedings of the Science Education Research Association, Nicosia, 1, 85-92.

Brasil. (1996). Lei de Diretrizes e Bases da Educação Nacional. Disponível em http://www.presidencia.gov.br/ccivill_o3/leis/19394.htm

Brasil. (2012). Diretrizes Curriculares Nacionais para o Ensino Médio.

Brasil. (2010). Diretrizes Curriculares Nacionais Gerais para a Educação Básica.

Brasil. (2011). Microdados do Censo Escolar da Educação Básica. Disponível em:http://portal.inep.gov.br/basica-levantamentos-acessar

Brasil. (2012). Microdados do Censo Escolar da Educação Básica. Disponível em http://portal.inep.gov.br/basica-levantamentos-acessar

Brasil. (2013). Microdados do Censo Escolar da Educação Básica. Disponível em http://portal.inep.gov.br/basica-levantamentos-acessar

Brasil. (2014). Microdados do Censo Escolar da Educação Básica. Disponível em http://portal.inep.gov.br/basica-levantamentos-acessar

Corbin, J. e Strauss, A. (1998). Basics of qualitative research: Techniques and procedures for developing grounded theory. Londres: Sage Publications.

Creswell, J. (2005) Educational research: Planning, conducting, and evaluating quantitative and qualitative research. New Jersey: Merrill Prentice Hall.

Franco, C. e Bonamino, A. (1999). O ENEM no contexto das políticas para o ensino médio. Química Nova na Escola, 10, 26-31.

Garcia, P. S., Prearo, L. L. C., Romero, M. C. e Bassi, M. S. (2015). Desempenho escolar: Uma análise do IDEB das cidades da Região do Grande ABC. Em P. S. Garcia e L. Prearo (Orgs.), Avaliação da educação escolar no Grande ABC Paulista: Primeiras aproximações (pp. 41-70). São Paulo: Plêiade.

Gonçalves Junior, W. P. (2012). Avaliações em larga escala e o professor de física (Dissertação, Universidade Federal do Rio de Janeiro, Rio de Janeiro).

Instituto Brasileiro de Geografia Estatística (IBGE). (2010). Dados do Censo. Disponível em http://www.censo2010.ibge.gov.br/dados_divulgados

Instituto Nacional de Estudos e Pesquisas Educacionais Anísio Teixeira (INEP). (1998). Enem: Documento básico. MEC/INEP: Brasília.

Johnson, R. B. e Onwuegbuzie, A. J. (2004). Mixed methods research: A research paradigm whose time has come. Educational Researcher, 33(7), 14-26. doi:10.3102/0013189x033007014 
Krawczyk, N. (2011). Reflexão sobre alguns desafios do Ensino Médio no Brasil hoje. Cadernos de Pesquisa, 41(144), 752-769.

Krawczyk, N. (2013). Novos formatos escolares para novas demandas sociais: O Ensino Médio Integrado. Archivos de Ciencias de la Educación, 6, 1-13.

Lopes, A. C. e López, S. B. (2010). A performatividade nas políticas de currículo: Caso do Enem. Educação em Revista, 26(1), 89-110. doi:10.1590/s0102-46982010000100005

Néri, M. (2009) Motivos da evasão escolar. São Paulo: FGV.

Observatório de Educação do Grande ABC. (2015). São Caetano do Sul: Relatório anual.

Onwuegbuzie, A. J. e Johnson, R. B. (2006). The validity issue in mixed research, research in the schools, 13(1), 48-63.

Ramalho, I. B. e Núñes, B. L. (2011). Aprendendo com o Enem: Reflexões para melhor se pensar o ensino e a aprendizagem das ciências naturais e da matemática. Brasília: Liber Livro.

Relação Anual de Informações (RAIS). (2014). Relatório de dados.

Salva, S., Ramos, E. S. e Ramos, N. V. (2016). Juventude e ensino médio: Os processos de afastamento da escola. Educação, 41(1), 171-182. doi:10.5902/1984644413957

Siegel, S. (1975). Estatística não-paramétrica para as ciências do comportamento. São Paulo: McGrawHill.

Soares Neto, J. J., Jesus, G. R., Karino, C. A. e Andrade, D. F. (2013). Uma escala para medir a infraestrutura escolar. Estudos em Avaliação Educacional, 24(54), 78-99. doi:10.18222/eae245420131903

Tashakkori, A., Teddlie, C. (2010). Putting the human back in "Human Research Methodology": The researcher in mixed. Journal of Mixed Methods Research, 4(4), 271-277. doi: $10.1177 / 1558689810382532$

Travitzki, R. (2013). ENEM: Limites e possibilidades do Exame Nacional do Ensino Médio enquanto indicador de qualidade escolar (Tese doutoral, Faculdade de Educação, Universidade de São Paulo, São Paulo).

Vianna, H. M. (2003). Avaliações nacionais em larga escala: Análises e propostas. Estudos em Avaliação Educacional, 27, 41-76. doi:10.18222/eae02720032177

Viggiano, E., Guariglia, C. E. e Mattos, C. R. (2010). O Exame Nacional do Ensino Médio: Avaliação institucional ou seleção para o ensino superior? Em C. Leite, A. F. Moreira, J. A. Pacheco, J. C. Morgado e A. Mouraz (Orgs.), Debater o currículo e os seus campos: Actas do IX Colóquio sobre questões curriculares (pp. 5000-5015). Porto: Centro de Investigação e Intervenção Educativas.

Viggiano, E., Guariglia, C. E. e Mattos, C. R. (diciembre, 2011). Uma investigação sobre o impacto do sistema de seleção unificada nas questões sobre energia no Exame Nacional do Ensino Médio. VIII Encontro de Pesquisa em Educação em Ciências, Rio de Janeiro.

Viggiano, E. e Mattos, C. R. (2013). O desempenho de estudantes no Enem 2010 em diferentes regiões. Revista Brasileira de Estudios Pedagógicos, 94(237), 417-438. doi:10.1590/s217666812013000200005 


\section{Breve CV de los autores}

\section{Paulo Sérgio Garcia}

Pedagogo, Mestre (1997) e Doutor em educação pela Faculdade de Educação da Universidade de São Paulo (2011). Possui Pós-Doutorado (2014) com a realização de estudos em escolas no Brasil e na Itália. Foi representante da América do Sul no International Board IOSTE - International Organization for Science and Technology Education (2008-2010). É professor da Universidade Municipal de São Caetano do Sul (Departamento de Educação) e coordenador do Projeto de Observatório da Região do Grande $\mathrm{ABC}$ Paulista, onde desenvolve pesquisas ligadas às escolas, às políticas educacionais e à avaliação educacional. É membro do International Congress for School Effectiveness and Improvement (ICSEI), pesquisador da Faculdade de Educação da Universidade de São Paulo e do Grupo Inter-institucional Desempenho Escolar e Inclusão Acadêmica - IDEIA, Universidade Federal de Santa Maria.

\section{Leandro Campi Prearo}

Matemático, Mestre e Doutor em Métodos Quantitativos e Informática pela. É professor da Universidade Municipal de São Caetano do Sul (Mestrado em Educação; Mestrado e Doutorado em Administração; Graduação em Ciências Econômicas) e coordenador técnico do Projeto de Observatório da Região do Grande ABC Paulista, onde desenvolve pesquisas ligadas às escolas, às políticas educacionais e à avaliação educacional. É diretor do Instituto de Pesquisas da Universidade Municipal de São Caetano do Sul.

\section{Maria do Carmo Romero}

Possui graduação em Ciências Econômicas pela Universidade Municipal de São Caetano do Sul (1978), mestrado em Administração pela Universidade de São Paulo (1996) e doutorado em Administração pela Universidade de São Paulo (2006). Atualmente é professor da graduação da Universidade Municipal de São Caetano do Sul, pró-reitora de pós graduação e pesquisa da Universidade Municipal de São Caetano do Sul, professor titular da Universidade Municipal de São Caetano do Sul e professor do programa de pós graduação -m/d da Universidade Municipal de São Caetano do Sul. Membro do grupo de pesquisa do Observatório da Região do Grande ABC Paulista, onde desenvolve pesquisas ligadas às escolas, às políticas educacionais e à avaliação educacional.

\section{Marcos Sidnei Bassi}

Possui graduação em Direito pela Universidade Municipal de São Caetano do Sul (2009), graduação em Ciências Socias pela Universidade Municipal de São Caetano do Sul (1987), mestrado em Administração de Empresas pela Fundação Getulio Vargas - SP (1995) e Doutorado em Ciências Sociais - Sociologia, pela PUC-SP. Atualmente é Reitor da Universidade Municipal de São Caetano do Sul (USCS). Tem experiência na área de Administração, com ênfase em Administração Pública. Membro do grupo de pesquisa do Observatório da Região do Grande ABC Paulista, onde desenvolve pesquisas ligadas às escolas, às políticas educacionais e à avaliação educacional. 